\title{
USO DE PRODUTOS NA PÓS-COLHEITA DE FLORES: UMA REVISÃO DE LITERATURA
}

\author{
Nohora Vélez Carvajal ${ }^{1}$ \\ Patricia Alvarez Cabanez ${ }^{2}$ \\ José Carlos Lopes ${ }^{3}$
}

Resumo: Na pós-colheita de flores são utilizados diversos produtos para manter sua qualidade até chegar no consumidor final. Com este trabalho objetivou-se fazer um levantamento das publicações feitas sobre a floricultura, que relacionavam a conservação de flores pós-colheita com os processos fisiológicos. Os critérios de inclusão de trabalhos utilizados foram: publicações recentes; que retratavam o assunto em questão; que abordavam as palavras chaves como floricultura; pós-colheita; qualidade; flores tropicais e etileno. Através desta pesquisa observou-se que existe a necessidade de continuar com o estudo do uso de diferentes soluções na pós-colheita de flores. Conclui-se que não existe um tratamento ou fórmula única capaz de resolver todos os problemas da pós-colheita de flores, há um conjunto de ações e tratamentos necessários a serem seguidos para manter a qualidade, desde a obtenção de cultivares com características próprias de boa vida pós-colheita, a um manejo agronômico livre de doenças e pragas, e manter a cadeia do frio logo da colheita.

Palavras-chave: Floricultura; Qualidade; Flores tropicais; Etileno.

\footnotetext{
1 Doutorado em Produção Vegetal / Universidade Federal do Espírito Santo - Centro de Ciências Agrárias e Engenharias, Brasil. E-mail: nora_velez@yahoo.com.

2 Doutorado em Produção Vegetal / Universidade Federal do Espírito Santo - Centro de Ciências Agrárias e Engenharias, Brasil. E-mail: patriciacabanez@gmail.com.

3 Professor do Departamento de Produção Vegetal / Universidade Federal do Espírito Santo - Centro de Ciências Agrárias e Engenharias, Brasil. E-mail: jcufes@bol.com.br.
} 